\title{
Step-By-Step Occlusal Rehabilitation for Bulimic Patient.
}

\author{
Lee Wei May ${ }^{1}$ andLim Ghee Seong ${ }^{1 *}$ \\ *Department of Restorative Dentistry,University of Malaya, Malaysia
}

*Corresponding author: Lim Ghee Seong, Department of Restorative Dentistry, Faculty of Dentistry, University of Malaya, Kuala Lumpur, Malaysia

\section{Introduction}

Tooth wear or tooth surface loss is a general term used to denote surface loss of dental hard tissues from causes other than developmental ones, dental caries and trauma [1]. Often tooth wear is always presented with myriads of clinical presentation such as erosion, attrition, abrasion and abfraction. It is crucial to understand the definition of each tooth wear etiology and identify them during clinical examination. As this will affect the clinical management of the patients and their treatment outcome later. In the present article, the focus is placed on dental erosion in bulimic patient. Dental erosion is the irreversible loss of dental hard tissue due to a chemical process of acid dissolution but not involving bacterial plaque acid, and not directly associated with mechanical and traumatic factors, or even dental caries.

\section{Bullimic Neroxia}

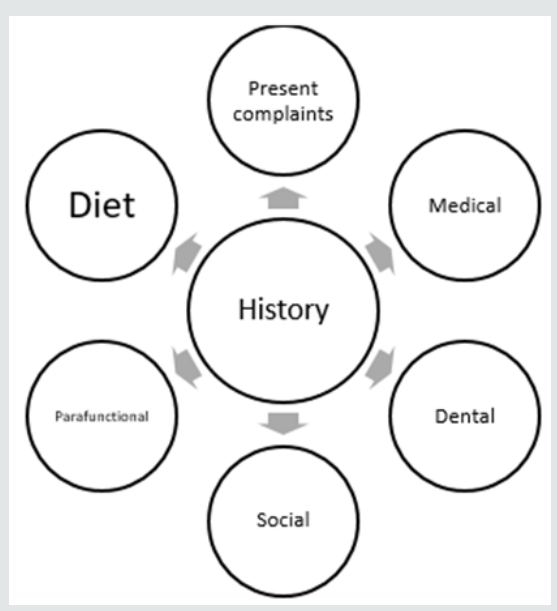

Figure 1: History taking related to tooth wears [13].Dental Management of Bulimic Patients

According to the World HealthOrganization World Mental Health Surveys involving 14 country, 1 percent of the population was diagnosed with bulimia nervosa (Kessler et al., 2013). In Malaysia, the prevalence of eating disorder from 1995 to 2011 increases from $0.7 \%$ to $19.8 \%$ (Gan, Nasir, Zalilah, \&Hazizi, 2011; Indran\& Mohamed Hatta, 1995). Lack of data regarding bulimic disorder warranted the need for further studies in our society. Bulimia nervosaFigure 1 is an intense pre-occupation with body weight and shape, with regular episodes of overeating associated with extreme measures to counteract the feared effects of the overeating (Hay \&Claudino, 2015).

\section{Oral Findings}

Dental erosion occurs because of purging by vomiting will only be apparent 6 months after onset (Hermont et al., 2014).The source of acid in bulimic patient comes from the gastric juice has a $\mathrm{PH}$ about 1.0 to 1.3. During purging, the vomit contacts the palatal aspects of maxillary anterior teeth. At times, this chemical activity eventually undermines the palatal surfaces causing incisal fractures and chipping, further complicates with the over eruption of the mandibular teeth.Erosions involving posterior teeth may erode the tooth tissue surrounding restorations, leaving the restoration with a raised island like appearance. This is known as perimylolysis. If this is left untreated, dental hypersensitivity is commonly reported and loss of occlusal contact may lead to loss of vertical dimension. Furthermore, because of insertion of objects to induce vomiting, traumatic lesions may be found on the palate and oropharynx of bulimic patients. Dry mouth related to dehydration; antidepressant drugs may lead to high caries risk. On the other hand, parotid enlargement, angular cheilitis, candidiasis, glossitis and oral mucosal ulceration are also commonly reported amongst bulimic patients (Touyz et al., 1993).A successful treatment planning depends on accurate diagnoses and appropriate decision making, thus proper history taking, and examinations are important prior to commencement of treatment [2]. First and foremost, present complains of the patient should be taken, very often patient's expectations of treatment are different from dental practitioners 
[3]. What concern the patient the most (aesthetic, mastication, discomfort) and the expectations of patient should be evaluated and noted during this stage. Particularly for this article, a thorough medical history regarding patient's eating disorder should be taken as bulimia nervosa is often associated with other medical problems such as electrolyte abnormalities, abnormal heart function, gastrointestinal complication and endocrine abnormalities. It will be helpful if dental practitioner can liaise with patient's psychiatrist and have a list of medications taken by the patient.Furthermore, if it is deemed relevant, any history of pain and tooth sensitivity should be taken. Previous dental treatment done will give the clinician an idea about patient's motivations level towards dental treatment. If patient has underwent preventive measurements previously, baseline records are important to check the outcome before proceeding treatment. On top of this, oral hygiene regime such as does patient brush teeth right after vomiting, types of toothbrush, toothbrushing techniques are important in determining the etiology of tooth wears.Very often patient will not disclose their social history when a friend or family is present. As tooth wear is often multifactorial, it is beneficial to probe more about other eating disorders, alcohol abuse problems, recreational drug abuse, smoking etc. Other than that, parafunctional habits such as bruxism, clenching, rumination will be questioned during history taking.A diet analysis sheet Figure 2 is a good tool to provide clear individualized preventive advice. Emphasis should be made on frequent intrinsic acid attacks or frequency of forced vomiting because of its extremely low $\mathrm{pH}$ and high titratable acidity. It is known binge eating often involves sugary food which leads to high caries rate (Rytömaa, Järvinen, Kanerva, \& P. Heinonen, 1998).

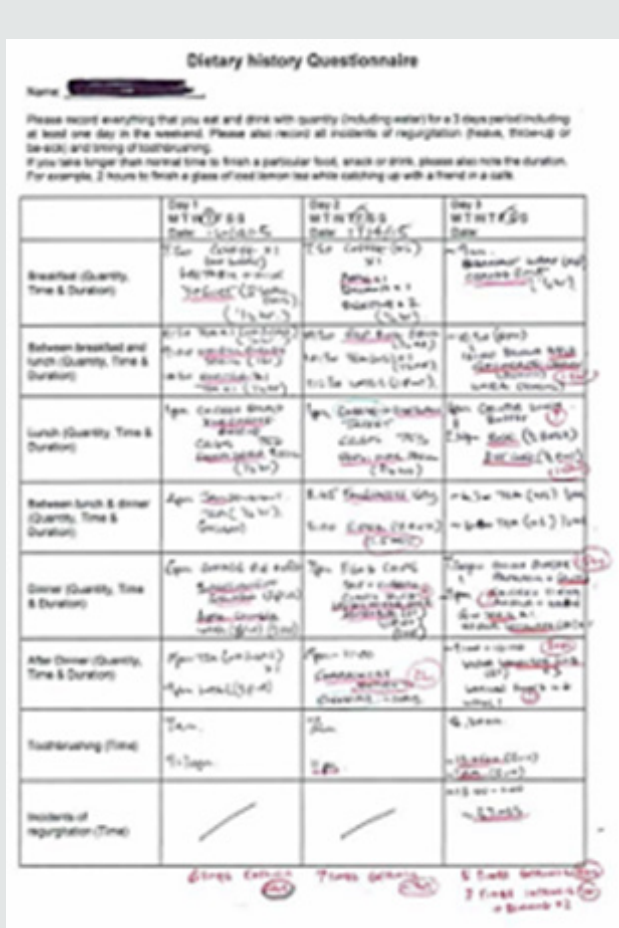

Figure 2: An example of completed diet sheet to study extrinsic and intrinsic factors with brushing habits [13].
Proper extraoral examination should be done as follows [4]:

a. Meticulous investigations on temporomandibular joints and muscles (bilateral muscle and jaw palpation, presence of any joint or muscle tenderness, clicking, crepitation, maximum jaw opening, mandibular deviation on opening or closure or any associated aches/pain should be noted).

b. Inverted lip profile and overclosure because of loss of vertical dimension.

c. Enlargement of parotid gland which often found in bulimic patient.

d. Facial vertical proportion.

e. Assessment of freeway space with various techniques.

f. Smile line, lip line and midline discrepancy.

Intraoral examination must include a detailed soft tissue, hard tissue examination and saliva analysis (quantity, quality, $\mathrm{PH}$ ). Presence of buccal keratosis, scalloping of tongue or signs of xerostomia may give clues to the possible etiology.Level of oral hygiene should be recorded together with undertaking of basic periodontal assessment [4]. Good oral hygiene is the key to success for all restorations and it is a useful parameter to show patient's level of interest and commitment. Efficacy of plaque control should be measured by bleeding scores not by plaque scores(Figure 3). Plaque scores inform only about performance on the day while bleeding scores give a longer term view [5].Complete dental charting detailing the presence of absence of teeth, dental caries, restorations, failed restorations, factures, different types of tooth wear should be completed.According to Robb and friends, distinguishing characteristics among disordered eating patients regarding caries include a predisposition to cervical caries and/or a leathery lesion of dentine leaving large areas of enamel undermined [6].Besides recording the location of tooth wear (localized or generalized), The Tooth Wear Index of Smith and Knight is most used to describe the severity of tooth wear[7]. On the other hand, patient presenting with generalized wear may be assigned to three categories according to Turner and Missirlian [8].

\begin{tabular}{|c|c|c|}
\hline Score $^{*}$ & Surface & Criterion \\
\hline 0 & $\begin{array}{c}\text { BLOI } \\
\text { C }\end{array}$ & $\begin{array}{l}\text { No loss of enamel surface characteristics } \\
\text { No change of contour }\end{array}$ \\
\hline 1 & $\begin{array}{l}\text { BLOI } \\
\text { C }\end{array}$ & $\begin{array}{l}\text { Loss of enamel surface characteristics } \\
\text { Minimal loss of contour }\end{array}$ \\
\hline 2 & $\begin{array}{c}\text { BLO } \\
1 \\
\text { C }\end{array}$ & $\begin{array}{l}\text { Enamel loss just exposing dentine }<1 / 3 \text { of the surface } \\
\text { Enamel loss just exposing dentine } \\
\text { Defect less than } 1 \mathrm{~mm} \text { deep }\end{array}$ \\
\hline 3 & $\begin{array}{c}\text { BLO } \\
\text { I } \\
\text { C }\end{array}$ & $\begin{array}{l}\text { Enamel loss just exposing dentine }>1 / 3 \text { of the surface } \\
\text { Enamel loss \& substantial dentine loss but no pulp exposure } \\
\text { Defect } 1.2 \mathrm{~mm} \text { deep }\end{array}$ \\
\hline 4 & $\begin{array}{c}\text { BLO } \\
1 \\
\mathrm{C}\end{array}$ & $\begin{array}{l}\text { Complete enamel loss, or pulp exposure, or } 2^{\circ} \text { dentine exposure } \\
\text { Pulp exposure, or } 2^{\circ} \text { dentine exposure } \\
\text { Defect more than } 2 \mathrm{~mm} \text { deep, or pulp exposure, or } 2^{\circ} \text { dentine exposure }\end{array}$ \\
\hline
\end{tabular}

Figure 3: Tooth Wear Index of Smith and Knight. [10].

Overall examination of the general alignment of both arches including presences (or absence) of crowding, rotations, titling, 
drifting, spacing, over eruption, reduced interarch space, mobility of teeth, overjet and overbite should be recorded. On top of this, a comprehensive occlusal analysis is mandatory which includes presence of stable Centric Occlusion (CO) and tooth contacts in intercuspal position. If patient cannot be readily manipulated into Retruded Centric Position (RCP) due to protective neuromuscular reflexes, the use of deprogramming devices ranging from leaf gauge, anterior deprograming device "Lucia jig", cotton rolls or full coverage stabilization splints will be helpful. Moreover, it is important to identify the first point of tooth contact in CRFigure 4, also known as the Retruded Contact Point (RCP). Dentist should take note whether the slide from CR to CO has a larger vertical or horizontal component. This is because the latter may be vital in providing the space requirements for dental restorative materials when considering a re-organized approach. Besides that, lateral and protrusive jaw record (canine guided or group function) are needed to facilitate occlusal analysis on mounted cast. If patient is wearing removable prosthesis, examination of retention, stability and occlusion is a must in providing a diagnosis.After detailed history taking and examinations, hopeless teeth which is deemed unrestorable will be extracted [9]. This may not always be evident immediately as some teeth may require investigation such as sensibility test, good quality long cone radiograph to make or confirm a diagnosis, while decisions regarding periodontally compromised teeth may be influenced by the patient's efforts in plaque control.Good quality study cast mounted on semi adjustable articulator in maximum intercuspation and centric relation will permit an assessment of occlusion in the absence of soft tissue/ muscular interferences. Presence of occlusal interference during excursive and protrusive movements are more easily determined. The vertical and horizontal components of the slide from CR to CO can also be examined at this stage. Diagnostic wax mockup may be fabricated with the desired final occlusal scheme as prescribed by the operator. They form a useful visual aid and communication tool to assist in the evaluation of aesthetics, tooth shape, length/height and inclination [10]. Furthermore, it can be transferred into vacuum formed PVC matrix that can be used as a tooth reduction guide, assist the fabrication of provisional restorations and definitive prosthesis. The wax up occlusion should aim to provide occlusal stability, based on principles of a mutually protective scheme which should provide:

\begin{tabular}{|c|l|}
\hline Score & Criterion \\
\hline 1 & $\begin{array}{l}\text { Excessive wear with loss of vertical dimension of } \\
\text { occlusion }\end{array}$ \\
\hline 2 & $\begin{array}{l}\text { Excessive wear without loss of vertical dimension of } \\
\text { occlusion but space available }\end{array}$ \\
\hline 3 & $\begin{array}{l}\text { Excessive wear without loss of vertical dimension, but } \\
\text { with limited space. }\end{array}$ \\
\hline
\end{tabular}

Figure 4: Turner and Missirlian Index for Generalized Tooth Wear [12].

a. Simultaneous stable bilateral tooth contacts.

b. Centric Relation (CR) coincident with Centric Occlusion (CO). c. Disclusion of the posterior teeth, upon lateral and protrusive mandibular movements.

d. Anterior teeth disclusion when posterior teeth contact in maximum intercuspation.

e. Shared/ even anterior guidance.

f. Canine guided occlusion, with planned group function upon loss of canine guidance (or where the canine tooth may be unsuitable as a guiding unit), with the absence of working or non-working side interference[11].

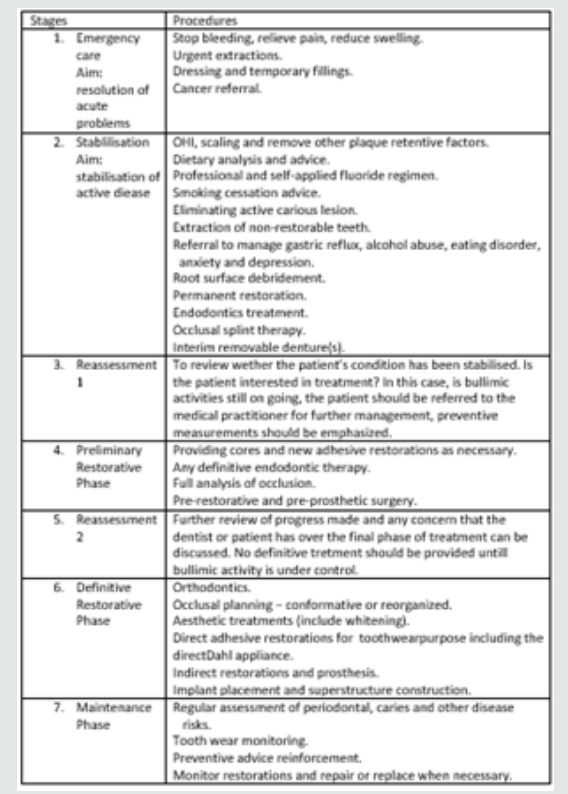

Figure 5: Sequence of treatments systematically.

The treatment can be broken down into sequence of stages as shown below:

In most of tooth wear cases, initial treatment should focus on preventive and conservative measurements. For example, dietary advice on reducing the frequency, duration and amount of carbonated, sports, alcoholic drinks which will reduce salivary secretion and hence less protection [12]. A coating with dentine agent or sealant application may protect tooth substance from acid attack and reduce hypersensitivity. Patient is advised to avoid toothbrushing shortly after vomiting, a neutral sodium fluoride mouth rinse/gel or mouth is recommended to combat acid damage(Figure 5). Splint may be prescribed to protect teeth during episodes of vomiting for bulimicpatient, but precise instructions must be given to avoid the splint to become a reservoir for acid produced[13]. Regular follow up with medical practitioner for bulimic activities or other psychological issues is important in treating the underlying cause of tooth wear. These preventive measurements aim to prevent further pathological tooth wear with the hope that the wear rate may ultimately return to that a physiological rate[14]. It is worth spending an appropriate interval of time to assess the efficacy of preventive regime before active restorative intervention to reassess and reestablish treatment plan 
to restore the dentition with possible minimal loss of hard and soft tissue(Figure 6). Monitoring progression of tooth wear can be undertaken by high quality clinical intraoral photographs or periodic study cast every 6-12 monthly [4].

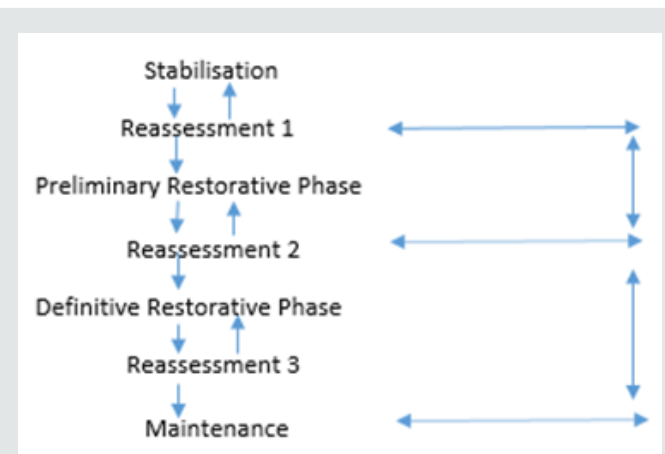

Figure 6: Stages of treatment [6].

\section{Conclusion}

Dentist should be equipped with knowledge regarding oral manifestation of bulimic patients to be able to detect warning signs of eating disorder. Prompt referral and organized dental management help in limiting the damaging effects and promote better patients' outcome.

\section{References}

1. Hattab FN, Yassin OM (2000) Etiology and diagnosis of tooth wear: A literature review and presentation of selected cases. International Journal of Prosthodontics 13(2): 101-107.

2. Ibbetson R (1999) Tooth surface loss: Treatment planning. British dental journal 186(11): 552-558.
3. Neumann LM, Caryn Christensen, Catherine Cavanaugh (1989) Dental esthetic satisfaction in adults. The Journal of the American Dental Association 118(5): 565-570.

4. SB Mehta, S Banerji, BJ Millar, JM Suarez Feito (2012) Current concepts on the management of tooth wear: part 1. Assessment, treatment planning and strategies for the prevention and the passive management of tooth wear. British dental journal 212(1): 17-27.

5. Yim VKC (2017) Tooth wear: Screening, diagnosis and management in general dental practice. Dental Update 44(6): 502-517.

6. Robb N, Smith B (1996) Anorexia and bulimia nervosa (the eating disorders): Conditions of interest to the dental practitioner. Journal of dentistry 24(1-2): 7-16.

7. Smith B (1984) An index for measuring the wear of teeth. Br Dent J 156(12): 435-438.

8. Turner KA, Missirlian DM (1984) Restoration of the extremely worn dentition. Journal of Prosthetic Dentistry 52(4): 467-474.

9. Halperin Sternfeld M, Levin L (2013) Do we really know how to evaluate tooth prognosis? A systematic review and suggested approach. Quintessence International 44(5): 447-456.

10. SB Mehta, S Banerji, BJ Millar, JM Suarez Feito (2012). Current concepts on the management of tooth wear: part 2 . Active restorative care 1 : the management of localized tooth wear. British dental journal 212(2): 7382.

11. Stuart CSH (1963) Concepts of occlusion. Dent Clin North Am 7(591).

12. Young W (2001) The oral medicine of tooth wear. Australian Dental Journal 46(4): 236-250.

13. Ferro KJ (2017) The Glossary of Prosthodontic Terms. J Prosthet Dent 117(5): 1-105.

14. Imfeld T (1996) Dental erosion. Definition, classification and links. European journal of oral sciences 104(2): 151-155.
This work is licensed under Creative Commons Attribution 4.0 License

To Submit Your Article Click Here: Submit Article

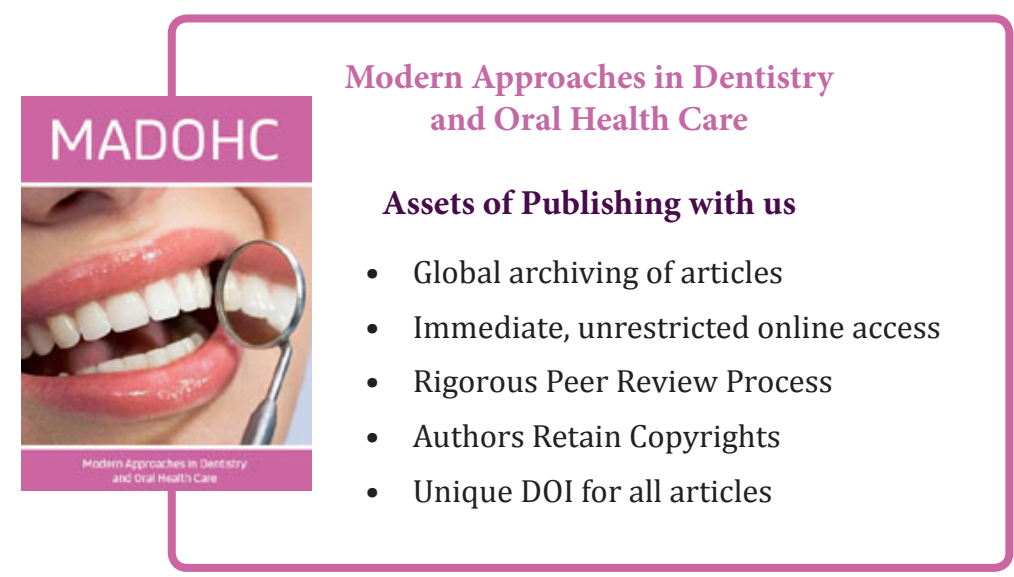

